\title{
Expert consensus for the diagnosis and treatment of patient with hyperuricemia and high cardiovascular risk: 2021 update
}

\author{
Claudio Borghi ${ }^{1 *}$, Justyna Domienik-Karłowicz ${ }^{2,3 *}$, Andrzej Tykarski ${ }^{4}$, \\ Krystyna Widecka ${ }^{5}$, Krzysztof J. Filipiak ${ }^{6}$, Miłosz J. Jaguszewski ${ }^{3,7}$, \\ Krzysztof Narkiewicz ${ }^{8}$, Giuseppe Mancia ${ }^{9}$ \\ ${ }^{1}$ Department of Medical and Surgical Sciences, University of Bologna, Italy \\ ${ }^{2}$ Department of Internal Medicine and Cardiology with the Center for Diagnosis and \\ Treatment of Venous Thromboembolism, Medical University of Warsaw, Poland \\ ${ }^{3}$ Club 30, Polish Cardiac Society, Poland \\ ${ }^{4}$ Department of Hypertension, Angiology and Internal Diseases, \\ Poznan University of Medical Sciences, Poznan, Poland \\ ${ }^{5}$ Department of Hypertension and Internal Medicine, Pomeranian Medical University, Szczecin, Poland \\ ${ }^{6}$ First Department of Cardiology, Medical University of Warsaw, Poland \\ ${ }^{7}$ First Department of Cardiology, Medical University of Gdansk, Poland \\ ${ }^{8}$ Department of Hypertension and Diabetology, Medical University of Gdansk, Poland \\ ${ }^{9}$ Università Milano-Bicocca, Milan, Italy
}

While fundamental concepts outlined in the 2018 consensus [1] will be revisited, emphasis will be placed on the more recent developments.

\section{Definition and epidemiology: Constantly increasing burden and importance of hyperuricemia}

Uric acid (UA) is the end product of purine metabolism, and its concentration in blood can increase in humans, great apes, and dalmatian dogs as a consequence of a genetic mutation that occurred millions of years ago and contribute to human evolution from less evolved species [2]. These elevated plasma levels of UA are the final result of almost three different mechanisms under genetic control and involve UA production, renal excretion, and gut absorption [3]. Under physiological conditions, UA synthesis and excretion are balanced in the body. Once this balance is disturbed, it leads to hyperuricemia (HU). Typically, male UA levels greater than $7 \mathrm{mg} / \mathrm{dL}(420 \mu \mathrm{mol} / \mathrm{L})$ and female UA levels greater than $6 \mathrm{mg} / \mathrm{dL}(360 \mu \mathrm{mol} / \mathrm{L})$ are considered hyperuricemia.

The latest scientific data published after our first consensus $[4,5]$ indicates that mean serum uric acid (sUA) has increased constantly according to the prevalence of concomitant diseases in many populations, while the prevalence of $\mathrm{HU}$ increases with age and is higher in men than premenopausal women due to estrogen's positive influence on urate excretion by the kidneys [4]. The United States National Health and Nutrition Examination Survey (NHANES 2007-2016) estimated the HU prevalence to be $20.2 \%$ for men ( 22.8 million) and $20.0 \%$ for women (24.4 million). In simple terms, 1 in 5 men and 1 in 5 women suffer from HU. The prevalence of sUA levels $>6.0 \mathrm{mg} / \mathrm{dL}$ was $32.3 \%$ overall (75.8 million), $49.5 \%$ among men (55.8 million), and $16.4 \%$ among women (20.0 million).

Address for correspondence: Justyna Domienik-Karłowicz, MD, PhD, Department of Internal Medicine and Cardiology with the Center for Diagnosis and Treatment of Venous Thromboembolism, Medical University of Warsaw, ul. Lindleya 4, 00-005 Warszawa, Poland, tel: +48 2250211 44, fax: +48 2250213 63, e-mail: jdomienik@tlen.pl

Received: 8.01.2021

Accepted: 8.01.2021

*Equal contribution

This article is available in open access under Creative Common Attribution-Non-Commercial-No Derivatives 4.0 International (CC BY-NC-ND 4.0) license, allowing to download articles and share them with others as long as they credit the authors and the publisher, but without permission to change them in any way or use them commercially. 
The overall mean sUA level was $5.39 \mathrm{mg} / \mathrm{dL}$ (95\% confidence interval [CI] 5.34-5.45), with mean sUA levels of $6.04 \mathrm{mg} / \mathrm{dL}$ and $4.79 \mathrm{mg} / \mathrm{dL}$ among men and women, respectively. Moreover, the prevalence rates of HU remained stable between 2007 and 2016 ( $p$ for trend $>0.05$ ) [5]. Of note, the prevalence of $\mathrm{HU}$ increased with age, with the highest being $27.8 \%$ (3.1 million) among individuals aged 80 years or older. Among patients aged 65 years or older, the prevalence of $\mathrm{HU}$ was $27.2 \%$ (12.6 million) [5]. Recently published data by the Irish health system indicate that from 2006 to 2014, the prevalence of $\mathrm{HU}$ increased from $19.7 \%$ to $25.0 \%$ in men and from $20.5 \%$ to $24.1 \%$ in women $(\mathrm{p}<0.001)$. Moreover, age-specific prevalence increased in all groups from 2006 to 2014, and the magnitudes of the increases were similar for each age category [6].

The prevalence of HU increased significantly with worsening renal function, from $12.2 \%$ in patients with estimated glomerular filtration rate (eGFR) $>90 \mathrm{~mL} / \mathrm{min}$ to $63.9 \%$ in patients with eGFR $<15 \mathrm{~mL} / \mathrm{min}$ [6].

The adoption of a Western lifestyle by natives of other countries and cultures and a change in the socioeconomic background through immigration to Western countries and movement from rural to urban communities have influenced sUA levels $[7,8]$.

\section{The pathophysiological effect of hyperuricemia on cardiovascular disease: What matters more? Overproduction or underexcretion?}

First and foremost, an increased sUA level is the result of a purine/fructose-rich diet, genetic or environmental factors, metabolic disorders, as well as either: (1) its endogenous overproduction (due to, e.g., purine-rich diet, an error of purine metabolism affected by phoribosyl-pyrophosphate synthetase or purine salvage pathway influenced by hypoxanthine-xanthine phosphoribosyl transferase; cell breakdown or excessive purine turnover: lymphoproliferative diseases, myeloproliferative disease, polycythemia vera, Paget disease [9], psoriasis, tumor lysis, hemolysis, rhabdomyolysis, and exercise; [10] or - in most cases - by (2) insufficient excretion (caused by acute or chronic kidney disease [CKD], acidosis: lactic acidosis, ketoacidosis; hypovolemia, medication/ /toxin: diuretic, niacin, pyrazinamide, ethambutol, cyclosporin, beryllium, salicylates, lead, alcohol; sarcoidosis, hyperparathyroidism, hypothyroidism, Bartter syndrome, and Down syndrome [11-13].
It should be emphasized that due to the limitations of the current knowledge on what is more important for unfavorable cardiovascular effect of $\mathrm{HU}$ - overproduction of UA (increased activity of xanthine oxidase with reactive oxygen species formation) or limited excretion (effects of UA per se), the topic has become one of the hottest in the field of cardiovascular research and hyperuricemia. However, the mechanism of impaired oxidative mechanism which was widely described in a previous version of this document seems to be more consistent.

\section{Genetics: Possibilities for individualized diagnoses and care strategies?}

There is growing evidence that genetics and environmental factors play a key role in HU's development [14]. Considering HU's pathophysiological aspects, it can be divided into overproduction (liver) and underexcretion types (gut, kidney). Indeed, genome-wide association studies identified the genetic basis of HU as dominated by loci containing urate transporters and interacting proteins involved in the excretion of urate; among them SLC2A9 (GLUT9), ABCG2, SLC22A11, SLC17A1-SLC17A4, and PDZK1; and proteins associated with metabolic pathways (e.g., GCKR, A1CF, IGF1R) [15]. Among these, GLUT9 and ABCG2 were recognized as the most significant [16]. Indeed, SLC2A9 (GLUT9) has a key role in urate transport and reabsorption. GLUT9-encoded protein is useful in urate excretion into urine and the reabsorption of urate into the blood. Differences among variants of GLUT9 also influence the excretion of UA in urine and its reabsorption to blood [17]. Systematic analysis of GLUT9's variants confirms its key role in the treatment of HU. Moreover, the ABCG2 gene (BCRP) is engaged in intestinal excretion and UA transport in proximal tubule epithelial cells [18]. Mutations in ABCG2 impede proper sUA regulation and lead to HU. Of note, in hemochromatosis patients, iron/ /heme overload enhances the activity of xanthine oxidase and - through p53 - causes the reduction of ABCG2 expression. This leads to a reduction in UA intestinal excretion and subsequent accumulation in tissue and serum, causing hereditary hemochromatosis-associated arthritis [19].

Among many others, one should acknowledge organic anion transporters 10 (OAT10, SLC22A13), acting as a key part of urate transport from urine to the blood; lactate dehydrogenase D (LDHD), decreasing excretion of UA [20]; 
hypoxanthine-guanine phosphoribosyltransferase (HGPRT) whose deficiency caused by an HPRT1 mutation leads to elevated UA levels in the blood, which are associated with Kelley-Seegmiller syndrome, Lesch-Nyhan syndrome, and HU [21]; mitochondrial seryl-tRNA synthetase precursor, a member of the class II tRNA synthetase family, which is involved in the ligation of serine to tRNA (Ser) and is involved in selenocysteinyl-tRNA (sec) biosynthesis in mitochondria [22]; xanthine dehydrogenase $(\mathrm{XDH})$, influencing the oxidation of hypoxanthine to xanthine and the oxidation of xanthine to UA [23], therefore reducing the levels of xanthine oxidoreductase. Drabkin et al. [20] confirmed that a mutation could cause HU in LDHD within the putative catalytic site of the encoded d-lactate dehydrogenase, which results in increased blood levels of d-lactate - typically present in blood in miniscule amounts. As a consequence, excessive renal secretion of d-lactate in exchange for UA reabsorption culminates in HU. In line with the human phenotype, injection of d-lactate into naive mice resulted in HU [20].

These advances lead to a clear-cut approach to individualized patient care; genetic data can be informative about the prognosis in patients suffering from $\mathrm{HU}$ and help clinicians select dosage of urate-lowering therapy (ULT) and offer the correct advice on lifestyle changes.

\section{Recent studies linking hyperuricemia to cardiovascular disease}

\section{Hyperuricemia and ischemic heart disease}

We look forward to the results of the ALL-HEART study, which is a multicenter, controlled, prospective, randomized trial, examining the effects of allopurinol (up to $600 \mathrm{mg}$ daily) vs. no treatment on cardiovascular outcome (non-fatal myocardial infarction, non-fatal stroke or cardiovascular death) in patients with coronary artery disease. The secondary goals are to determine the cost-effectiveness of adding allopurinol to usual therapy, determine whether allopurinol improves the quality of life, and to determine the safety and tolerability of giving allopurinol to patients with ischemic heart disease (without a history of gout). The main inclusion criteria were patients of 60 years of age and over and ischemic heart disease. The main exclusion criteria were history of gout, eGFR $<30 \mathrm{~mL} / \mathrm{min}$, and moderate-to-severe heart failure and significant hepatic disease [24].

\section{Hyperuricemia and hypertension}

An ample body of evidence widely acknowledges that the association between an increase in relative risk of hypertension and high levels of sUA remains independent of traditional risk factors [25-33]. A substantial meta-analysis of 18 studies confirmed an increase of $13 \%$ in the incidence of new-onset hypertension for every $1 \%$ increase in sUA levels [25]. The PAMELA (Pressioni Arteriose Monitorate e Loro Associazioni) study confirmed that a rise in sUA by $1 \mathrm{mg} / \mathrm{dL}$ was associated with a significant increase in the risk of developing the new-onset home and ambulatory hypertension (odds ratio [OR] 1.34, 95\% CI 1.06-1.7, $\mathrm{p}=0.015$; OR 1.29, 95\% CI 1.05-1.57, $\mathrm{p}=0.014$; respectively) [26]. Finally, the Saku study confirmed that HU predicted the risk of developing hypertension was independent of alcohol drinking status [34].

\section{Hyperuricemia and stroke}

Serum uric acid plays a key and influential role in the physiopathology of stroke [35]. Kim et al. [36] reported that HU was associated with a significantly higher risk of both stroke incidence (relative risk [RR] 1.41) and mortality (RR 1.36) in their meta-analyses of unadjusted study estimates. Accordingly, Zhong et al. [37] in their meta-analysis confirmed similar results; elevated sUA levels were significantly associated with an increased risk of stroke in both men (RR 1.10 per $1 \mathrm{mg} / \mathrm{dL}$ increase in sUA) and women (RR 1.11 [1.09-1.13]). In the newest study to date; CIRCS investigators presented that elevated sUA level is an independent predictor of total stroke in women but not in men. The positive association present in women was mostly attributable to ischemic stroke and was more pronounced among nonusers of antihypertensive medication [38].

\section{Hyperuricemia and metabolic syndrome}

As mentioned above, several studies demonstrated that sUA level is associated with metabolic syndrome, high body mass index (BMI), waist circumference, high fasting blood glucose levels, and dyslipidemia [39]. Shirasawa et al. [40] analyzed data derived from 96,863 participants and confirmed that the adjusted OR for HU was considerably increased in obesity (with central obesity) compared with normal weight, regardless of sex (men: OR 2.12, 95\% CI 2.03-2.21; women: OR 3.54, 95\% CI 3.21-3.90) and was statistically increased in normal weight with central obesity 
compared to normal weight (men: OR 1.44, 95\% CI 1.36-1.52; women: OR 1.41, 95\% CI 1.27-1.57). They concluded that middle-aged Japanese adults with normal weight but having central obesity should be screened using a combination of BMI and waist to height ratio and be educated about how to prevent HU [40].

\section{Hyperuricemia and atrial fibrillation}

Currently, evidence on serum urate with the risk of atrial fibrillation (AF) is mainly from cross sectional studies, based on prevalent AF cases, and were limited by only a 1-time measurement of serum urate. However, in a large prospective cohort study with 123,238 participants conducted from 2006 to 2012, both an increased cumulative average and elevations in serum urate over time were associated with increased risk of incident $\mathrm{AF}$ (adjusted hazard ratio [HR] 1.91, 95\% CI 1.32-2.76, $\mathrm{p}=0.001$ for trend). The combination of high sUA and high-sensitivity C-reactive protein levels was associated with a significantly increased risk of incident AF (adjusted HR 2.63, 95\% CI 1.63-4.23). Li et al. [41] provided evidence of an association between a relatively common treatable metabolic alteration (higher serum urate) and a common cardiac rhythm disorder (AF) with substantial morbidity and mortality. Moreover, Hong et al. [42] confirmed that the association between sUA and AF was significant $(\mathrm{p}=0.001)$ after adjusting for potential confounding factors.

\section{Hyperuricemia and liver diseases}

The relationship between $\mathrm{HU}$ and liver disease has not been clearly described. Undoubtedly, the increased level of sUA is the result of a diet rich in purine and fructose, genetic and environmental factors, metabolic disorders, as well as endogenous overproduction or - in most cases - impaired excretion of UA [43-46]. Uric acid synthesis is mainly influenced by phosphoribosyl pyrophosphate synthetase and the purine pathway [46]. Some publications indicate the association of increased levels of sUA with non-alcoholic fatty liver disease, which is a part of metabolic syndrome, and chronic hepatitis. In experimental studies, the UA-stimulated expression of aldose reductase in both cultured hepatocytes (HepG2 cells) and hyperuricemic rat livers were associated with endogenous fructose production triglyceride accumulation through UA-induced oxidative stress and stimulation of the nuclear transcription factor activated $\mathrm{T} 5$ cells (NFAT5). Uric acid also potentiated the effects of elevated glucose levels to stimulate the accumu- lation of triglycerides in the liver. Hyperuricemic rats exhibited elevated hepatic aldose reductase expression, endogenous fructose accumulation, and fat accumulation was significantly reduced by allopurinol co-administration. Thus, HU is correlated with the occurrence of hypertriglyceridemia and non-alcoholic fatty liver disease, which secondarily induces the development of non-alcoholic steatohepatitis [47, 48].

Jang et al. [49] investigated UA levels and their relationship to disease progression in 373 patients with biopsy-confirmed chronic hepatitis $\mathrm{C}$ (CHC) enrolled in interferon-based antiviral therapy. In this study HU was defined as UA levels $>7 \mathrm{mg} / \mathrm{dL}$ in men and $>6.0 \mathrm{mg} / \mathrm{dL}$ in women. Hyperuricemia was found in $15.8 \%$ of CHC patients, but UA levels did not differ between $\mathrm{CHC}$ patients and the control group of healthy subjects matched for sex and age $(5.54 \pm 1.20 \mathrm{mg} / \mathrm{dL}$ vs. $5.45 \pm 1.45 \mathrm{mg} / \mathrm{dL}$, $\mathrm{p}=0.3)$. Logistic regression analysis showed that factors related to $\mathrm{HU}$ in men included $\mathrm{BMI}(\mathrm{OR} / \mathrm{CI}$ $1.12 / 1.05-1.30, \mathrm{p}=0.006)$ and advanced fibrosis (F3-4) (OR/CI 0.27/0.09-0.83, p = 0.02), while factors associated with $\mathrm{HU}$ in women included eGFR (OR/CI 0.97/0.95-0.99, $\mathrm{p}=0.02)$ and diabetes $(\mathrm{OR} / \mathrm{CI} 3.03 / 1.11-8.25, \mathrm{p}=0.03)$. There was a significant downward trend in sUA levels with the progression of fibrosis in men $(6.21 \pm 1.03 \mathrm{mg} /$ $/ \mathrm{dL}, 5.82 \pm 1.16 \mathrm{mg} / \mathrm{dL}$, and $5.44 \pm 1.28 \mathrm{mg} / \mathrm{dL}$ in stages F0-2, F3 and F4, respectively, trend $\mathrm{p}=0.01$ ), indicating that $\mathrm{HU}$ was inversely related to the severity of liver disease in men with CHC [49]. Petta et al. [50] do not share this opinion; in a study of 496 patients with biopsy-confirmed CHC treated with pegylated interferon and ribavirin, there was no independent association between UA levels and necroinflammatory activity, fibrosis, nor sustained virologic response. However, the association of HU with the severity of steatosis was confirmed (OR 3.176, 95\% CI 1.828-5.517, p <0.001), which could potentially be a therapeutic target in the treatment of CHC [50]. Moreover, Jang et al. [51], in a group of 213 patients, where $\mathrm{HU}$ was defined as UA levels $>7.0 \mathrm{mg} / \mathrm{dL}$ in men and $>6.0 \mathrm{mg} / \mathrm{dL}$ in women, showed that sUA levels decreased significantly after eradication of hepatitis $\mathrm{C}$ virus by the use of direct antiviral drugs. Improvement was only observed in patients with fibrosis-4 ratio $($ FIB- 4$)<6.5$ (37.1\% vs. $25.7 \%, \mathrm{p}=0.001)$. The multivariate analysis showed that factors associated with significantly reduced sUA levels were FIB-4 < $6.5(\mathrm{OR} / 95 \%$ CI 3.22/1.04-9.95, $\mathrm{p}=0.04)$ and eGFR $<60 \mathrm{~mL} / \mathrm{min} / 1.73 \mathrm{~m}^{2}(\mathrm{OR} / 95 \% \mathrm{CI}$ 4.34/1.94-9.73, $\mathrm{p}<0.001$ [51]. 


\section{Hyperuricemia and COPD}

Identification of prognostic biomarkers for chronic obstructive pulmonary disease (COPD) may help improve therapy for patients at high risk. In univariate analysis, HU was associated with a higher risk of mortality in patients with COPD (HR 2.29, 95\% CI 1.07-4.88, $\mathrm{p}=0.032$ ). Further analysis confirmed that HU was independently associated with a higher risk of mortality in patients with COPD (HR 2.68, 95\% CI 1.18-6.09, $\mathrm{p}=0.019$ ) [52]. Moreover, it was recently published that sUA could activate the nucleotide-binding oligomerization domain-like receptor family pyrin domain-containing 3 (NLRP3) inflammasome, leading to interleukin (IL)- $1 \beta$ secretion. In COPD patients, UA and uric ratio with creatinine (UCR) were positively associated with white blood cells, $\mathrm{C}$-reactive protein, and IL- $1 \beta$. COPD smokers had lower UA and UCR values. Standard COPD therapy did not affect UA or UCR, while patients with cardiovascular diseases (CVD) had higher UA, but not UCR, levels. Multiparameter models of UA and UCR that included IL- $1 \beta$ were able to correctly classify $86 \%$ and $90 \%$ of cases, respectively [53].

\section{Current uric acid thresholds predicting cardiovascular events: Including improved cardiovascular risk estimation}

As described in a previous document [1], sUA is considered an independent factor in the development of a wide variety of vascular disorders: hypertension [54], metabolic syndrome [55, 56], coronary artery disease [57], diabetes [58], cerebrovascular disease [59, 60], CKD [61], as well as other CVD $[62,63]$ and - conversely - these comorbidities increase the incidence of HU [64]. It is worth paying attention to other conditions, both those from the genre of metabolic syndrome (e.g., non-alcoholic fatty liver, non-alcoholic steatohepatitis) and those whose presence may affect the clinical course of disorders in the cardiovascular system (e.g., COPD [65] or incident asthma in men [66]).

What we know so far, is that some studies have found a robust association between sUA level and CVD not only in patients with clearly diagnosed HU but also in those with values considered normal to high > 5.2-5.5 mg/dL [67-69]. Moreover, this relationship concerned both subclinical and clinical manifestations of diseases [64], and remained highly significant even after renal function adjustment.

Of note, the Working Group on sUA and cardiovascular risk within the Italian Society of Hy- pertension designed the URRAH (Uric Acid Right for Heart Health) study, whose aim was to assess - in a group of 22,714 subjects - the level of UA above which the independent risk of CVD may increase in a significant manner in the general population [70]. Virdis et al. [71] confirmed that the threshold UA levels were $4.7 \mathbf{~ m g} / \mathbf{d L}$ (95\% CI $1.21-1.93 \mathrm{mg} / \mathrm{dL}$ ) for increasing all-cause mortality, $5.6 \mathbf{~ m g} / \mathrm{dL}(95 \%$ CI $4.99-6.21 \mathrm{mg} / \mathrm{dL})$ for increasing cardiovascular mortality, and were significantly lower than levels referenced in clinical diagnostic criteria [71]. Considering the sex of the patients, the threshold for sUA for all-cause mortality was $5.4 \mathrm{mg} / \mathrm{dL}$ (95\% CI 4.80-6.57) in men and $4.7 \mathrm{mg} / \mathrm{dL}$ (95\% CI 4.40-5.10) in women. Most importantly for clinical practice is that the novel sUA thresholds allow for a significant net reclassification of - and improvement in - the Heart Score risk chart's present values for all-cause and cardiovascular mortality, 0.26 and 0.27 , respectively.

In summation, this large-sample study led to a significant improvement in risk classification of the well-validated and guideline-recommended scale, the Heart Score. Further analysis for factors not included in the Heart Score such as hematocrit, diuretics, alcohol consumption, BMI, and eGFR did not significantly affect results [71]. The results reported by Virdis et al. [71] are largely superimposable over those obtained in several different populations of subjects enrolled in observational studies and show an increase in the relative risk of major cardiovascular events in the presence of sUA levels ranging between 4.5 and $5.5 \mathrm{mg} / \mathrm{dL}$ [72-75]. Previously reported investigations in smaller groups gave partially corroborative results specifically in the following contexts: in comparison to the Framingham Risk Score [72], in later life only [73], in patients undergoing percutaneous coronary interventions due to acute coronary syndrome [74], and in hypertensive patients; conflicting results were yielded in NHANES III [75]. The lower threshold level reported for CVD compared with gout can be explained by the causative role of the oxidative stress associated with the production of sUA by xanthine-oxidase that occurs with lower concentrations of serum urate and is largely independent of the inflammatory role of UA deposition.

A large body of evidence confirms the contribution of $\mathrm{HU}$ to the worsening of cardiovascular, diabetic, lipid, and renal diseases [76-78]; thereby supporting the conclusion that increased sUA levels correlate with elevated cardiovascular risk $[79,80]$ and further stressing the importance of a redefinition of threshold levels referred to during 
identification of patients at risk of CVD in the presence of hyperuricemia.

URRAH researchers identified the prognostic cut-off values of sUA in predicting fatal and morbid heart failure; sUA more than $5.34 \mathrm{mg} / \mathrm{dL}$ (CI 4.37 -5.6 , sensitivity 52.32 , specificity $63.96, \mathrm{p}<0.0001$ ) was the univariate prognostic cut-off value for all heart failure, whereas sUA more than $4.89 \mathrm{mg} / \mathrm{dL}$ (CI 4.78-5.78, sensitivity 68.29 , specificity 49.11 , $\mathrm{p}<0.0001$ ) was the prognostic cut-off value for fatal heart failure [81]. Moreover, Huang et al. [82] analyzed ten studies involving 12,854 acute heart failure patients and confirmed that acute heart failure patients with the highest sUA levels had an increased risk of all-cause mortality (risk ratio [RR] $1.43,95 \%$ CI 1.31-1.56) and a combined endpoint of death or readmission (RR 1.68, 95\% CI 1.33-2.13), after adjusting for potential variables. Therefore, elevation in sUA levels significantly increased risks of all-cause mortality and combined endpoint of death or readmission by $11 \%$ and $12 \%$, respectively, for every $1 \mathrm{mg} / \mathrm{mL}$, they were elevated [82]. Also, URRAH researchers adjusted for such confounders as age, arterial hypertension, diabetes, CKD, smoking habits, ethanol intake, BMI, hematocrit, low-density lipoprotein cholesterol, and use of diuretics in multivariate Cox regression analyses and identified an independent association between sUA and fatal myocardial infarction across the whole database (HR 1.381, 95\% CI 1.096-1.758, $\mathrm{p}=0.006)$ and in women, specifically (HR 1.514, 95\% CI 1.105-2.075, $\mathrm{p}<0.01$ ), but not in men [83].

\section{Hyperuricemia and cardiovascular} events: A high serum uric acid level and its influence on cardiovascular outcome

As we mentioned earlier, several studies have confirmed the relationship between sUA and CVD mortality [26, 84]. However, Rahimi-Sakak et al. [85] performed a meta-analysis of 44 prospective cohort studies with dose-response analysis published between 2000 and 2018 to determine the relationship between sUA and CVD mortality. Pooled results confirmed a significant positive association between sUA levels and risk of CVD mortality (HR 1.45, 95\% CI 1.33-1.58, $\left.\mathrm{I}^{2}=79 \%\right)$. Sub-group analysis yielded that this association was stronger in women compared to men. Also, there was a significant non-linear association between sUA levels and CVD mortality risk $(r=0.0709, p=0.001)$ [85]. In a cross-sectional study, Lee et al. [86] investigated the relationship of sUA with CVD risk in the Korean adult general population (8781 participants from first and second years of the Seventh Korea National Health and Nutrition Examination Survey 2016-2017). There was a significant association of sUA with 10-year CVD risk scores after adjusting for physical activity, BMI, serum creatinine, and alcohol consumption in both sexes $(p<0.001)$; at sUA levels of $6.9 \mathrm{mg} / \mathrm{dL}$, the CVD risk was lowest [86].

\section{Hyperuricemia treatment and cardiovascular outcomes: Allopurinol remains first-line urate-lowering therapy}

In a systematic review of 24 guidance documents, 19 of them provided target levels for long-term sUA control, most of which recommended $6.0 \mathrm{mg} / \mathrm{dL}$ (or $360 \mu \mathrm{mol} / \mathrm{L}$ ), except the South African guidelines, which recommended $5.0 \mathrm{mg} / \mathrm{dL}$ $(300 \mu \mathrm{mol} / \mathrm{L})$ [87]. Also, the Polish Society of Hypertension Guidelines 2019 recommend $5.0 \mathrm{mg} / \mathrm{dL}$ level for long-term sUA control [88]. Still, the definition of $\mathrm{HU}$ varies greatly across clinical trials, making epidemiological reports somewhat inconsistent and difficult to compare.

Xanthine-oxidase inhibitors (XOI), especially allopurinol, are still recommended by almost all guidelines as a first-line ULT. The results on febuxostat have recently been implemented after publication of the FAST trial (long-term cardiovascular safety of febuxostat compared with allopurinol in patients with gout: a multicenter, prospective, randomized, open-label, non-inferiority trial) [89, 90] that reported divergent results from those described by the CARES (Cardiovascular Safety of Febuxostat and Allopurinol in Patients with Gout and Cardiovascular Morbidities) study [91].

\section{Febuxostat: Further clinical trials needed?}

Febuxostat, a nonpurine XOI, is recommended in patients refractory or intolerant to allopurinol and requires no dose limitation in CKD stages $1-3$. Febuxostat induces potent inhibition of XO and greater hypouricemic activity than the commonly used allopurinol doses [92]. However, preliminary results from a safety trial with febuxostat versus allopurinol, mainly based on a large-scale, randomized study design has suggested a modestly higher rate of cardiovascular events with febuxostat [93]. Based on the preceding study's findings, treatment with febuxostat in patients at high cardiovascular risk has not been recommended. Another safety oriented randomized controlled trial reporting results of a 32-month follow-up $(n=6190)$, demonstrated the compa- 
rable effects of febuxostat and allopurinol on the primary cardiovascular end-point with a higher rate in the secondary objectives of all-cause and cardiovascular mortality in the febuxostat group than in the allopurinol group (HR for death from any cause 1.22 , 95\% CI 1.01-1.47; HR for cardiovascular death $1.34,95 \%$ CI 1.03-1.73) [91]. In the meantime, a meta-analysis of 35 studies did not show a significant difference between febuxostat and allopurinol in cardiovascular events (RR 1.69, 95\% CI 0.54-5.34, $\mathrm{p}=0.37$ ) [94]. Moreover, in the FREED study of over 1000 elderly patients with $\mathrm{HU}, 25 \%$ relative risk reduction in composite with death to any cause, cerebrovascular disease, non-fatal coronary artery disease, heart failure requiring hospitalization, an arteriosclerotic disease requiring treatment, renal impairment, and $\mathrm{AF}$ was observed in the febuxostat group compared to the non-febuxostat group. There was no difference in cardiovascular clinical outcomes examined separately with febuxostat versus control treatment.

In contrast, the European Medicines Agency (EMA)-required Febuxostat versus Allopurinol Streamlined Trial (FAST), published in the Lancet, does not support the finding of an increased cardiovascular risk of febuxostat, despite using higher (EMA-approved) dosages compared to the CARES trial [90]. In 6128 patients (with previous CVD), for the incidence of the primary endpoint (a composite of hospitalization for non-fatal myocardial infarction or biomarker-positive acute coronary syndrome, non-fatal stroke, or cardiovascular death), on-treatment, febuxostat (172 patients [1.72 events per 100 patient-years]) was non-inferior to allopurinol (241 patients [2.05 events per 100 patient-years]; adjusted HR 0.85 [95\% CI 0.70-1.03], p < 0.0001) [90]. In editorial comments, Bardin and Richette [89] underlined that patients in the CARES study had more severe gout than those in the FAST study and that all patients in CARES had a history of CVD in contrast to 2046 (33.4\%) of 6128 in FAST. No excess of deaths was observed in this subgroup of patients in FAST. Still, their group size might be insufficient to fully assess febuxostat risk in patients with severe CVD [89]. Thus, further clinical trials are needed to clarify this issue and provide clear evidence for the withdrawal of the Food and Drug Administration alert in this issue.

\section{Uric acid and COVID-19}

There are not many studies on the relationship between sUA and coronavirus disease 2019 (COVID-19). However, of note that favipiravir, a purine nucleic acid analog and antiviral agent studied in Japan to treat COVID-19, has frequent side effects [95]. Favipiravir's action causes it as a moderate inhibitor of organic anion transporters 1 and 3 (OAT1 and OAT3), which are involved in UA excretion in the kidney, as well as by its influence on UA reuptake via urate transporter 1 (URAT1) in the proximal renal tubules. Elevated UA levels were found to return to normal after discontinuation of favipiravir, and favipiravir is not recommended for long periods to treat viral infection [96, 97]. Moreover, in a Japanese, prospective, randomized, open-label trial of early versus late favipiravir treatment in hospitalized patients with COVID-19, 84.1\% developed transient HU [98].

\section{Management strategies: Updated five-step recommendations for the treatment of patients with increased serum uric acid levels (Fig. 1)}

\section{STEP 1: Assess serum uric acid level}

The measurement of sUA concentration is recommended as a part of screening in cardiac/ /hypertensive patients by experts of both the European Society of Cardiology and the European Society of Hypertension [99].

Our recommendation remains unchanged: the optimal target of sUA levels should be $6 \mathrm{mg} / \mathrm{dL}$ $(360 \mu \mathrm{mol} / \mathrm{L})$. Serum uric acid levels should be monitored regularly and maintained at $<6 \mathrm{mg} / \mathrm{dL}$. Still, despite the lack of randomized controlled trials, one should consider an sUA target of $<5 \mathrm{mg} / \mathrm{dL}$ in patients with high cardiovascular risk comprised of at least two of the following: hypertension, diabetes, dyslipidemia, organ target organ damage or previous cardiovascular events.

\section{STEP 2: Check comorbidities and active treatments and stop the administration of drugs that influence serum uric acid}

Appropriate strategies should be defined and implemented in patients with HU, regarding more aggressive control of concomitant risk factors and the use of drugs indirectly affecting UA levels. Efficient management of concomitant diseases that influence sUA levels, such as hypertension, type 2 diabetes, metabolic syndrome, CKD, and CVD [56, 61-64] should be the procedure of choice. In clinical scenarios, feasible changes should be considered if the potential benefits exceed the potential harms, particularly:

- Diuretics, among them hydrochlorothiazide - switching from hydrochlorothiazide to alternative antihypertensive agents, if possible; 


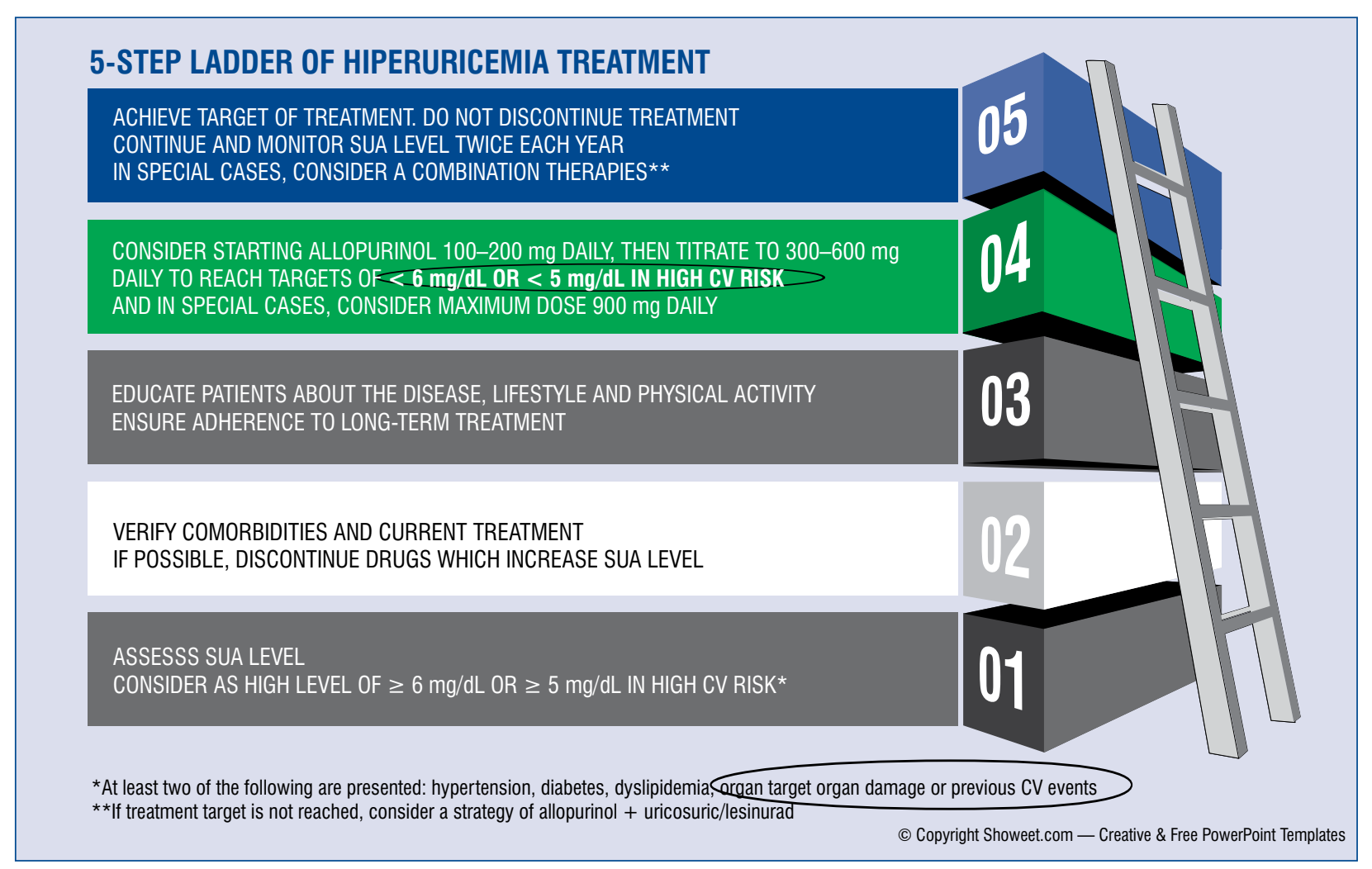

Figure 1. Management strategy for patients suffering from hiperuricemia; CV — cardiovascular; SUA — serum uric acid.

- Angiotensin II receptor blockers (ARBs) although losartan is the only antihypertensive drug that lowers sUA level [100], switching from other ARBs to losartan is NOT recommended;

- Low-dose acetylsalicylic acid (ASA) - cessation of low-dose ASA in primary cardiovascular prevention patients or switching to alternatives, if possible; cessation of low-dose ASA in secondary cardiovascular prevention patients is NOT recommended;

- Cholesterol-lowering agents - switching from cholesterol-lowering drugs to fenofibrate is NOT recommended.

Building multidisciplinary teams for optimal diagnostics and management strategies, with an appropriate estimation of HU's significance, is necessary. It is essential to improve adherence to clinical practice guidelines, raise awareness of $\mathrm{HU}$ and associated comorbidities, and prompt their more diligent and specific monitoring.

\section{STEP 3: Recommended life-style changes} are:

Among the most significant lifestyle changes

- Limiting intake of purines, including red meat and seafood;
- Limiting intake of high-fructose corn syrup. Based on the Third National Health and Nutrition Examination Survey, sUA levels increase with increasing sugar-sweetened soft drink intake. After adjusting for covariates, sUA levels associated with sugar-sweetened soft drink consumption categories $(<0.5,0.5-0.9$, $1-3.9$, and $\geq 4$ servings/day) were greater than those associated with no intake (by $0.08,0.15$, 0.33 , and $0.42 \mathrm{mg} / \mathrm{dL}$, respectively) (95\% CI $0.11-0.73, \mathrm{p}<0.001$ for trend) [101];

- Limiting alcohol. Limiting or abstaining from alcohol leads to decreased UA levels by $1.6 \mathrm{mg} / \mathrm{dL}$ compared to the control group [102];

- Weight loss and regular physical activity for patients who are overweight or obese [103, 104];

- Adding coffee, dairy products, cherries [100, 105], and ascorbic acid [106].

\section{STEP 4: Give xanthine oxidase inhibitors} as first-line therapy, titrated to achieve serum uric acid target

As mentioned earlier, allopurinol, XOI, is recommended as a first-line ULT in agreement with most of the guidelines. According to the summary of product characteristics of allopurinol, the rec- 
ommended initial allopurinol dosage is 100 to 200 $\mathrm{mg}$ daily in mild conditions, 300 to $600 \mathrm{mg}$ daily in moderate conditions, 700 to $900 \mathrm{mg}$ daily in severe conditions. The dosage should be titrated up to achieve the desired sUA target level [107].

Importantly - due to its renal excretion - in patients with CKD, impaired renal function may lead to retention of the drug and/or its metabolites (oxypurinol) with subsequent prolongation of plasma half-lives. For this reason, in severe CKD, it may be appropriate to use less than $100 \mathrm{mg}$ per day or to use single doses of $100 \mathrm{mg}$ at longer intervals than 1 day. In special situations and the presence of appropriate equipment, the dose should be adjusted to maintain plasma oxypurinol levels below $100 \mu \mathrm{mol} / \mathrm{L}(15.2 \mathrm{mg} / \mathrm{L})$. If allopurinol is used in dialysis patients, it should be administered at a 300-400 mg dose immediately after dialysis, but without additional doses on other days [107].

\section{STEP 5: Achieve targeted serum uric acid} levels, do not stop treatment, continue monitoring serum uric acid levels twice per year; in special cases, consider combined therapy

Only 2 in 5 patients with HU reached the target of sUA with this therapy [108]. Suppose that the sUA target cannot be achieved. In this case, the dose should be escalated with supervision up to $900 \mathrm{mg}$ of allopurinol, or the patient should be switched to benzbromarone or combined therapy of benzbromarone and allopurinol (STEP 5), except in patients with eGFR of $<30 \mathrm{~mL} / \mathrm{min}$ [109]. However, escalations should be performed carefully to achieve optimal treatment goals, mainly due to allopurinol hypersensitivity syndrome and severe cutaneous allergic reactions, usually after 8 weeks of therapy [110-112]. Factors that are known to contribute to the development of this syndrome include initial doses that are too high, CKD, accompanying use of diuretics, and the presence of HLA-B*5801 [113, 114].

Although high-dose allopurinol $(\geq 300 \mathrm{mg} / \mathrm{dL})$ is associated with a reduced risk of all-cause mortality $[7,115]$, consideration of an optimal dose seems to be a major factor design of future research.

Lesinurad is an oral selective inhibitor of URAT1 and OAT4 renal transporters, which increase renal UA excretion and lower sUA levels by inhibiting UA reabsorption. A dose of $200 \mathrm{mg}$ daily is recommended in combination with XOIs in patients who do not achieve treatment targets. Adding lesinurad can increase the efficiency of XOIs (compared to monotherapy) and help avoid maximal XOI dosages [116]. In a CLEAR study, lesinurad of $200 \mathrm{mg}$ or $400 \mathrm{mg}$ together with allopurinol significantly increased the proportion of patients who achieved the sUA target levels compared to allopurinol $(54.2 \%, 59.2 \%$, and $27.9 \%$, respectively, $\mathrm{p}<0.0001$ ) [117]. The approval of lesinurad was based on data from three pivotal phase III studies (CLEAR 1, CLEAR 2, and CRYSTAL), which assessed lesinurad $200 \mathrm{mg}$ and $400 \mathrm{mg}$ doses. The target sUA level was achieved by significantly more patients on lesinurad $200 \mathrm{mg}$ plus allopurinol group (CLEAR 1 and CLEAR 2 trials) or lesinurad $200 \mathrm{mg}$ plus febuxostat group (CRYSTAL study) compared to patients who received either XOI alone. The safety profile of lesinurad $200 \mathrm{mg}$ plus an XOI was comparable to allopurinol or febuxostat alone. To summarize, lesinurad, in combination with allopurinol, is a novel option for the treatment of $\mathrm{HU}$ in adults with gout who have not achieved their target sUA levels with allopurinol alone (STEP 5) [118, 119]. Once the sUA target is achieved continuously, ULT's dose should be maintained indefinitely with ongoing monitoring of sUA levels twice a year (STEP 5) [117, 120].

\section{Many unresolved questions still remain: Areas in need of further study}

First and foremost, UA's treatment target may still need to be reconsidered, especially since data from the URRAH study identified new cardiovascular thresholds and improved algorithms for assessing total cardiovascular risk. Still, there is a clear need for further evidence to support the treatment of asymptomatic HU, although a large body of evidence does show the beneficial effect of ULT on cardiovascular results.

\section{Most relevant recommendations: \\ The take home message for the clinical practitioners}

In conclusion, we would like to summarize our opinions that should be helpful to clinicians treating patients suffering from hyperuricemia and at high cardiovascular risk:

- 1 in 5 patients suffers from HU. The prevalence of $\mathrm{HU}$ is continuously increasing;

- All patients with HU should be effectively informed about environmental and pharmacological factors influencing HU, comorbidities, and cardiovascular risk factors; be advised about the immediately required lifestyle and 
diet modifications and weight loss, if necessary; and strict adherence to recommended treatments;

- Both patients and physicians of all specialties (especially primary care physicians, cardiologists, and pulmonologists) should strive to obtain and maintain lifelong sUA levels lower than $6 \mathrm{mg} / \mathrm{dL}$; for patients at high cardiovascular risk, the target level should be $5 \mathrm{mg} / \mathrm{dL}$;

- As mentioned earlier, allopurinol - a XOI - is recommended as a first-line ULT. According to the summary of product characteristics of allopurinol, the recommended initial allopurinol dosage is $100 \mathrm{mg}$ to $200 \mathrm{mg}$ daily in mild conditions, $300 \mathrm{mg}$ to $600 \mathrm{mg}$ daily in moderate conditions, and $700 \mathrm{mg}$ to $900 \mathrm{mg}$ daily in severe conditions;

- The dosage of XOIs should be titrated up to achieve the desired sUA target level and monitored twice a year thereafter to establish the correct level of sUA;

- If the sUA target levels are not reached, combined therapy of allopurinol + lesinurad might be considered.

Conflict of interest: Claudio Borghi has received honoraria for participation in national or international meetings from: Servier, Menarini Corporate, Daiichi Sankyo, Sanofi, Alfasigma, Gilead, Novartis; Justyna Domienik-Karłowicz has received speaker honoraria from Egis; Andrzej Tykarski has received honoraria for participation in national meetings from: Biopharm, Egis, Gedeon-Richter, Krka, Medtronic, Menarini, Servier; Krystyna Widecka has received speaking fees from: Servier, Krka, Egis, Berlin-Chemie/Menarini, Gedeon-Richter, Merck; Krzysztof J. Filipiak has received speaker honoraria from: Egis, Berlin-Chemie/Menarini; Miłosz J. Jaguszewski has speaker honoraria from: Egis, Servier; Krzysztof Narkiewicz has received speaker honoraria from: Egis, Berlin-Chemie/ /Menarini; Giuseppe Mancia has received honoraria for participation in national or international meetings from: AstraZeneca, Böhringer Ingelheim, Daiichi Sankyo, Medtronic, Menarini, Merck, Novartis, Recordati, Sandoz, Sanofi, Servier.

\section{References}

1. Borghi C, Tykarski A, Widecka K, et al. Expert consensus for the diagnosis and treatment of patient with hyperuricemia and high cardiovascular risk. Cardiol J. 2018; 25(5): 545-563, doi: 10.5603/ CJ.2018.0116, indexed in Pubmed: 30394510.

2. Bannasch D, Safra N, Young A, et al. Mutations in the SLC2A9 gene cause hyperuricosuria and hyperuricemia in the dog.
PLoS Genet. 2008; 4(11): e1000246, doi: 10.1371/journal. pgen.1000246, indexed in Pubmed: 18989453.

3. Bobulescu IA, Moe OW. Renal transport of uric acid: evolving concepts and uncertainties. Adv Chronic Kidney Dis. 2012; 19(6): 358-371, doi: 10.1053/j.ackd.2012.07.009, indexed in Pubmed: 23089270.

4. Zhu Y, Pandya BJ, Choi HK. Prevalence of gout and hyperuricemia in the US general population: the National Health and Nutrition Examination Survey 2007-2008. Arthritis Rheum. 2011; 63(10): 3136-3141, doi: 10.1002/art.30520, indexed in Pubmed: 21800283.

5. Chen-Xu M, Yokose C, Rai SK, et al. Contemporary Prevalence of Gout and Hyperuricemia in the United States and Decadal Trends: The National Health and Nutrition Examination Survey, 2007-2016. Arthritis Rheumatol. 2019; 71(6): 991-999, doi: 10.1002/art.40807, indexed in Pubmed: 30618180.

6. Kumar AUA, Browne LD, Li X, et al. Temporal trends in hyperuricaemia in the Irish health system from 2006-2014: A cohort study. PLoS One. 2018; 13(5): e0198197, doi: 10.1371/journal. pone.0198197, indexed in Pubmed: 29852506.

7. Feig DI, Kang DH, Johnson RJ. Uric acid and cardiovascular risk. N Engl J Med. 2008; 359(17): 1811-1821, doi: 10.1056/ NEJMra0800885, indexed in Pubmed: 18946066.

8. Johnson RJ, Titte S, Cade JR, et al. Uric acid, evolution and primitive cultures. Semin Nephrol. 2005; 25(1): 3-8, doi: 10.1016/j. semnephrol.2004.09.002, indexed in Pubmed: 15660328.

9. Arlot ME, Meunier PJ. Effects of two diphosphonates (EHDP and Cl2MDP) on serum uric acid in pagetic patients. Calcif Tissue Int. 1981; 33(3): 195-198, doi: 10.1007/BF02409437, indexed in Pubmed: 6456054.

10. Puig JG, Mateos FA. Clinical and biochemical aspects of uric acid overproduction. Pharm World Sci. 1994; 16(2): 40-54, doi: 10.1007/BF01880655, indexed in Pubmed: 8032341.

11. Dong H, Xu Y, Zhang X, et al. Visceral adiposity index is strongly associated with hyperuricemia independently of metabolic health and obesity phenotypes. Sci Rep. 2017; 7(1): 8822, doi: 10.1038/ s41598-017-09455-z, indexed in Pubmed: 28821853.

12. de Oliveira EP, Burini RC. High plasma uric acid concentration: causes and consequences. Diabetol Metab Syndr. 2012; 4: 12, doi: 10.1186/1758-5996-4-12, indexed in Pubmed: 22475652.

13. Perez-Ruiz F, Calabozo M, Erauskin GG, et al. Renal underexcretion of uric acid is present in patients with apparent high urinary uric acid output. Arthritis Rheum. 2002; 47(6): 610-613, doi: 10.1002/art.10792, indexed in Pubmed: 12522834.

14. Reginato AM, Mount DB, Yang I, et al. The genetics of hyperuricaemia and gout. Nat Rev Rheumatol. 2012; 8(10): 610-621, doi: 10.1038/nrrheum.2012.144, indexed in Pubmed: 22945592.

15. Nigam SK, Bush KT, Martovetsky G, et al. The organic anion transporter (OAT) family: a systems biology perspective. Physiol Rev. 2015; 95(1): 83-123, doi: 10.1152/physrev.00025.2013, indexed in Pubmed: 25540139.

16. Xu L, Shi Y, Zhuang S, et al. Recent advances on uric acid transporters. Oncotarget. 2017; 8(59): 100852-100862, doi: 10.18632/ oncotarget.20135, indexed in Pubmed: 29246027.

17. Vitart V, Rudan I, Hayward C, et al. SLC2A9 is a newly identified urate transporter influencing serum urate concentration, urate excretion and gout. Nature Genetics. 2008; 40(4): 437-442, doi: 10.1038/ng.106.

18. Ichida K, Matsuo H, Takada T, et al. Decreased extra-renal urate excretion is a common cause of hyperuricemia. Nat Commun. 2012; 3: 764, doi: 10.1038/ncomms1756, indexed in Pubmed: 22473008. 
19. Ristic B, Sivaprakasam S, Narayanan M, et al. Hereditary hemochromatosis disrupts uric acid homeostasis and causes hyperuricemia via altered expression/activity of xanthine oxidase and ABCG2. Biochem J. 2020; 477(8): 1499-1513, doi: 10.1042/ BCJ20190873, indexed in Pubmed: 32239172.

20. Drabkin M, Yogev Y, Zeller L, et al. Hyperuricemia and gout caused by missense mutation in d-lactate dehydrogenase. J Clin Invest. 2019; 129(12): 5163-5168, doi: 10.1172/JCI129057, indexed in Pubmed: 31638601.

21. Torres RJ, Puig JG. Hypoxanthine-guanine phosophoribosyltransferase (HPRT) deficiency: Lesch-Nyhan syndrome. Orphanet J Rare Dis. 2007; 2: 48, doi: 10.1186/1750-1172-2-48, indexed in Pubmed: 18067674.

22. Belostotsky R, Ben-Shalom E, Rinat C, et al. Mutations in the mitochondrial seryl-tRNA synthetase cause hyperuricemia, pulmonary hypertension, renal failure in infancy and alkalosis, HUPRA syndrome. Am J Hum Genet. 2011; 88(2): 193-200, doi: 10.1016/j.ajhg.2010.12.010, indexed in Pubmed: 21255763.

23. Chung HY, Baek BS, Song SH, et al. Xanthine dehydrogenase/ /xanthine oxidase and oxidative stress. Age (Omaha). 1997; 20(3): 127-140, doi: 10.1007/s11357-997-0012-2, indexed in Pubmed: 23604305.

24. Mackenzie IS, Ford I, Walker A, et al. Multicentre, prospective, randomised, open-label, blinded end point trial of the efficacy of allopurinol therapy in improving cardiovascular outcomes in patients with ischaemic heart disease: protocol of the ALL-HEART study. BMJ Open. 2016; 6(9): e013774, doi: 10.1136/ bmjopen-2016-013774, indexed in Pubmed: 27609859.

25. Grayson PC, Kim SY, LaValley M, et al. Hyperuricemia and incident hypertension: a systematic review and meta-analysis. Arthritis Care Res (Hoboken). 2011; 63(1): 102-110, doi: 10.1002/ acr.20344, indexed in Pubmed: 20824805.

26. Bombelli M, Ronchi I, Volpe M, et al. Prognostic value of serum uric acid: new-onset in and out-of-office hypertension and long-term mortality. J Hypertens. 2014; 32(6): 1237-1244, doi: 10.1097/HJH.0000000000000161, indexed in Pubmed: 24675682.

27. Krishnan E, Kwoh CK, Schumacher HR, et al. Hyperuricemia and incidence of hypertension among men without metabolic syndrome. Hypertension. 2007; 49(2): 298-303, doi: 10.1161/01. HYP.0000254480.64564.b6, indexed in Pubmed: 17190877.

28. Perlstein TS, Gumieniak O, Williams GH, et al. Uric acid and the development of hypertension: the normative aging study. Hypertension. 2006; 48(6): 1031-1036, doi: 10.1161/01. HYP.0000248752.08807.4c, indexed in Pubmed: 17060508.

29. Forman JP, Choi H, Curhan GC. Uric acid and insulin sensitivity and risk of incident hypertension. Arch Intern Med. 2009; 169(2): 155-162, doi: 10.1001/archinternmed.2008.521, indexed in Pubmed: 19171812

30. Mellen PB, Bleyer AJ, Erlinger TP, et al. Serum uric acid predicts incident hypertension in a biethnic cohort: the atherosclerosis risk in communities study. Hypertension. 2006; 48(6): 1037-1042, doi: 10.1161/01.HYP.0000249768.26560.66, indexed in Pubmed: 17060502.

31. Zhang W, Sun K, Yang Y, et al. Plasma uric acid and hypertension in a Chinese community: prospective study and metaanalysis. Clin Chem. 2009; 55(11): 2026-2034, doi: 10.1373/ clinchem.2009.124891, indexed in Pubmed: 19729471.

32. Shankar A, Klein R, Klein BEK, et al. The association between serum uric acid level and long-term incidence of hypertension: Population-based cohort study. J Hum Hypertens. 2006; 20(12): 937945, doi: 10.1038/sj.jhh.1002095, indexed in Pubmed: 17024135.
33. Sundström J, Sullivan L, D'Agostino RB, et al. Relations of serum uric acid to longitudinal blood pressure tracking and hypertension incidence. Hypertension. 2005; 45(1): 28-33, doi: 10.1161/01.HYP.0000150784.92944.9a, indexed in Pubmed: 15569852.

34. Tatsumi Y, Asayama K, Morimoto A, et al. Hyperuricemia predicts the risk for developing hypertension independent of alcohol drinking status in men and women: the Saku study. Hypertens Res. 2020; 43(5): 442-449, doi: 10.1038/s41440-019-0361-0, indexed in Pubmed: 31776471.

35. Ae R, Kanbay M, Kuwabara M. The causality between the serum uric acid level and stroke. Hypertens Res. 2020; 43(4): 354-356, doi: 10.1038/s41440-019-0346-z, indexed in Pubmed: 31988480.

36. Kim SY, Guevara JP, Kim KM, et al. Hyperuricemia and risk of stroke: a systematic review and meta-analysis. Arthritis Rheum. 2009; 61(7): 885-892, doi: 10.1002/art.24612, indexed in Pubmed: 19565556.

37. Zhong C, Zhong X, Xu T, et al. Sex-Specific relationship between serum uric acid and risk of stroke: a dose-response meta-analysis of prospective studies. J Am Heart Assoc. 2017; 6(4), doi: 10.1161/JAHA.116.005042, indexed in Pubmed: 28356280.

38. Li J, Muraki I, Imano H, et al. Serum uric acid and risk of stroke and its types: the Circulatory Risk in Communities Study (CIRCS). Hypertens Res. 2020; 43(4): 313-321, doi: 10.1038/ s41440-019-0385-5, indexed in Pubmed: 31988479.

39. Norvik JV, Storhaug HM, Ytrehus K, et al. Overweight modifies the longitudinal association between uric acid and some components of the metabolic syndrome: The Troms $\varnothing$ Study. BMC Cardiovasc Disord. 2016; 16: 85, doi: 10.1186/s12872-016-0265-8, indexed in Pubmed: 27165776.

40. Shirasawa T, Ochiai H, Yoshimoto T, et al. Cross-sectional study of associations between normal body weight with central obesity and hyperuricemia in Japan. BMC Endocr Disord. 2020; 20(1): 2, doi: 10.1186/s12902-019-0481-1, indexed in Pubmed: 31906920.

41. Li S, Cheng J, Cui L, et al. Cohort study of repeated measurements of serum urate and risk of incident atrial fibrillation. J Am Heart Assoc. 2019; 8(13): e012020, doi: 10.1161/ JAHA.119.012020, indexed in Pubmed: 31213103.

42. Hong M, Park JW, Yang PS, et al. A mendelian randomization analysis: The causal association between serum uric acid and atrial fibrillation. Eur J Clin Invest. 2020; 50(10): e13300, doi: 10.1111/eci.13300, indexed in Pubmed: 32474920.

43. Villegas R, Xiang YB, Elasy T, et al. Purine-rich foods, protein intake, and the prevalence of hyperuricemia: the Shanghai Men's Health Study. Nutr Metab Cardiovasc Dis. 2012; 22(5): 409-416, doi: 10.1016/j.numecd.2010.07.012, indexed in Pubmed: 21277179 .

44. Caliceti C, Calabria D, Roda A, et al. Fructose intake, serum uric acid, and cardiometabolic disorders: a critical review. Nutrients. 2017; 9(4), doi: 10.3390/nu9040395, indexed in Pubmed: 28420204.

45. Bleyer AJ, Hart TC. Genetic factors associated with gout and hyperuricemia. Adv Chronic Kidney Dis. 2006; 13(2): 124-130, doi: 10.1053/j.ackd.2006.01.008, indexed in Pubmed: 16580613.

46. Nakagawa T, Hu H, Zharikov S, et al. A causal role for uric acid in fructose-induced metabolic syndrome. Am J Physiol Renal Physiol. 2006; 290(3): F625-F631, doi: 10.1152/ajprenal.00140.2005, indexed in Pubmed: 16234313.

47. Sanchez-Lozada LG, Andres-Hernando A, Garcia-Arroyo FE, et al. Uric acid activates aldose reductase and the polyol pathway for endogenous fructose and fat production causing development 
of fatty liver in rats. J Biol Chem. 2019; 294(11): 4272-4281, doi: 10.1074/jbc.RA118.006158, indexed in Pubmed: 30651350.

48. Choi YJ, Shin HS, Choi HS, et al. Uric acid induces fat accumulation via generation of endoplasmic reticulum stress and SREBP-1c activation in hepatocytes. Lab Invest. 2014; 94(10): 1114-1125, doi: 10.1038/labinvest.2014.98, indexed in Pubmed: 25111690.

49. Jang TY, Yeh ML, Huang CI, et al. Association of hyperuricemia with disease severity in chronic hepatitis $\mathrm{C}$ patients. PLoS One. 2018; 13(11): e0207043, doi: 10.1371/journal.pone.0207043, indexed in Pubmed: 30395654.

50. Petta S, Macaluso FS, Cammà C, et al. Hyperuricaemia: another metabolic feature affecting the severity of chronic hepatitis because of HCV infection. Liver Int. 2012; 32(9): 1443-1450, doi: 10.1111/j.1478-3231.2012.02842.x, indexed in Pubmed: 22764879.

51. Jang TY, Huang CI, Yeh ML, et al. Improvement of hyperuricemia in chronic hepatitis $\mathrm{C}$ patients receiving directly acting antiviral agents. J Gastroenterol Hepatol. 2020; 35(3): 473-481, doi: 10.1111/jgh.14835, indexed in Pubmed: 31414504.

52. Zhang X, Liu L, Liang R, et al. Hyperuricemia is a biomarker of early mortality in patients with chronic obstructive pulmonary disease. Int J Chron Obstruct Pulmon Dis. 2015; 10: 2519-2523, doi: 10.2147/COPD.S87202, indexed in Pubmed: 26648710.

53. Rumora L, Hlapčić I, Popović-Grle S, et al. Uric acid and uric acid to creatinine ratio in the assessment of chronic obstructive pulmonary disease: Potential biomarkers in multicomponent models comprising IL-1beta. PLoS One. 2020; 15(6): e0234363, doi: 10.1371/journal.pone.0234363, indexed in Pubmed: 32502184.

54. Cannon PJ, Stason WB, Demartini FE, et al. Hyperuricemia in primary and renal hypertension. N Engl J Med. 1966; 275(9): 457-464, doi: 10.1056/NEJM196609012750902, indexed in Pubmed: 5917940.

55. Ford ES, Li C, Cook S, et al. Serum concentrations of uric acid and the metabolic syndrome among US children and adolescents. Circulation. 2007; 115(19): 2526-2532, doi: 10.1161/CIRCULATIONAHA.106.657627, indexed in Pubmed: 17470699.

56. Puig JG, Martínez MA. Hyperuricemia, gout and the metabolic syndrome. Curr Opin Rheumatol. 2008; 20(2): 187-191, doi: 10.1097/BOR.0b013e3282f4bled, indexed in Pubmed: 18349749.

57. Tuttle K, Short R, Johnson R. Sex differences in uric acid and risk factors for coronary artery disease. Am J Cardiol. 2001; 87(12): 1411-1414, doi: 10.1016/s0002-9149(01)01566-1.

58. Dehghan A, van Hoek M, Sijbrands EJG, et al. High serum uric acid as a novel risk factor for type 2 diabetes. Diabetes Care. 2008; 31(2): 361-362, doi: 10.2337/dc07-1276, indexed in Pubmed: 17977935.

59. Schretlen DJ, Inscore AB, Vannorsdall TD, et al. Serum uric acid and brain ischemia in normal elderly adults. Neurology. 2007; 69(14): 1418-1423, doi: 10.1212/01.wnl.0000277468.10236.f1, indexed in Pubmed: 17909154.

60. Lehto S, Niskanen L, Rönnemaa T, et al. Serum uric acid is a strong predictor of stroke in patients with non-insulin-dependent diabetes mellitus. Stroke. 1998; 29(3): 635-639, doi: 10.1161/01.str.29.3.635, indexed in Pubmed: 9506605.

61. Yu KH, Kuo CF, Luo SF, et al. Risk of end-stage renal disease associated with gout: a nationwide population study. Arthritis Res Ther. 2012; 14(2): R83, doi: 10.1186/ar3806, indexed in Pubmed: 22513212.

62. Abbott R, Brand F, Kannel W, et al. Gout and coronary heart disease: The Framingham study. J Clin Epidemiol. 1988; 41(3): 237-242, doi: 10.1016/0895-4356(88)90127-8.
63. De Vera MA, Rahman MM, Bhole V, et al. Independent impact of gout on the risk of acute myocardial infarction among elderly women: a population-based study. Ann Rheum Dis. 2010; 69(6): 1162 -1164, doi: 10.1136/ard.2009.122770, indexed in Pubmed: 20124358.

64. Borghi C, Rosei EA, Bardin T, et al. Serum uric acid and the risk of cardiovascular and renal disease. J Hypertens. 2015; 33(9): 1729-1741, doi: 10.1097/HJH.0000000000000701, indexed in Pubmed: 26136207.

65. Wattanachayakul P, Rujirachun P, Charoenngam N, et al. Chronic obstructive pulmonary disease (COPD) is associated with a higher level of serum uric acid. A systematic review and metaanalysis. Adv Respir Med. 2020; 88(3): 215-222, doi: 10.5603/ ARM.2020.0119, indexed in Pubmed: 32706105.

66. Wang H, Jia Y, Yi Mo, et al. High serum uric acid was a risk factor for incident asthma: an open cohort study. Risk Manag Healthc Policy. 2020; 13: 2337-2346, doi: 10.2147/RMHP.S277463, indexed in Pubmed: 33154685.

67. Feig DI, Johnson RJ. Hyperuricemia in childhood primary hypertension. Hypertension. 2003; 42(3): 247-252, doi: 10.1161/01. HYP.0000085858.66548.59, indexed in Pubmed: 12900431.

68. Nakagawa T, Tuttle KR, Short RA, et al. Hypothesis: fructose-induced hyperuricemia as a causal mechanism for the epidemic of the metabolic syndrome. Nat Clin Pract Nephrol. 2005; 1(2): 80-86, doi: 10.1038/ncpneph0019, indexed in Pubmed: 16932373.

69. Niskanen LK, Laaksonen DE, Nyyssönen K, et al. Uric acid level as a risk factor for cardiovascular and all-cause mortality in middle-aged men: a prospective cohort study. Arch Intern Med. 2004; 164(14): 1546-1551, doi: 10.1001/archinte.164.14.1546, indexed in Pubmed: 15277287.

70. Desideri G, Virdis A, Casiglia E, et al. Exploration into uric and cardiovascular disease: uric acid right for heArt health (URRAH) project, a study protocol for a retrospective observational study. High Blood Press Cardiovasc Prev. 2018; 25(2): 197-202, doi: 10.1007/s40292-018-0250-7, indexed in Pubmed: 29427170.

71. Virdis A, Masi S, Casiglia E, et al. Identification of the uric acid thresholds predicting an increased total and cardiovascular mortality over 20 years. Hypertension. 2020; 75(2): 302-308, doi: 10.1161/ HYPERTENSIONAHA.119.13643, indexed in Pubmed: 31813345

72. Perticone M, Tripepi G, Maio R, et al. Risk reclassification ability of uric acid for cardiovascular outcomes in essential hypertension. Int J Cardiol. 2017; 243: 473-478, doi: 10.1016/j. ijcard.2017.05.051, indexed in Pubmed: 28528984.

73. Dutta A, Henley W, Pilling LC, et al. Uric acid measurement improves prediction of cardiovascular mortality in later life. J Am Geriatr Soc. 2013; 61(3): 319-326, doi: 10.1111/jgs.12149, indexed in Pubmed: 23496291.

74. Tscharre M, Herman R, Rohla M, et al. Uric acid is associated with long-term adverse cardiovascular outcomes in patients with acute coronary syndrome undergoing percutaneous coronary intervention. Atherosclerosis. 2018; 270: 173-179, doi: 10.1016/j. atherosclerosis.2018.02.003.

75. Zalawadiya SK, Veeranna V, Mallikethi-Reddy S, et al. Uric acid and cardiovascular disease risk reclassification: findings from NHANES III. Eur J Prev Cardiol. 2015; 22(4): 513-518, doi: 10.1177/2047487313519346, indexed in Pubmed: 24431384.

76. Kleber ME, Delgado G, Grammer TB, et al. Uric acid and cardiovascular events: a mendelian randomization study. J Am Soc Nephrol. 2015; 26(11): 2831-2838, doi: 10.1681/ ASN.2014070660, indexed in Pubmed: 25788527.

77. Yan D, Wang J, Jiang F, et al. A causal relationship between uric acid and diabetic macrovascular disease in Chinese type 2 diabe- 
tes patients: A Mendelian randomization analysis. Int J Cardiol. 2016; 214: 194-199, doi: 10.1016/j.ijcard.2016.03.206, indexed in Pubmed: 27064641.

78. Kuwabara M, Borghi C, Cicero AFG, et al. Elevated serum uric acid increases risks for developing high LDL cholesterol and hypertriglyceridemia: A five-year cohort study in Japan. Int J Cardiol. 2018; 261: 183-188, doi: 10.1016/j.ijcard.2018.03.045, indexed in Pubmed: 29551256.

79. Borghi C, Desideri G. Urate-Lowering drugs and prevention of cardiovascular disease: the emerging role of xanthine oxidase inhibition. Hypertension. 2016; 67(3): 496-498, doi: 10.1161/HYPERTENSIONAHA.115.06531, indexed in Pubmed: 26865197.

80. Bove M, Cicero AF, Veronesi M, et al. An evidence-based review on urate-lowering treatments: implications for optimal treatment of chronic hyperuricemia. Vasc Health Risk Manag. 2017; 13: 23-28, doi: 10.2147/VHRM.S115080, indexed in Pubmed: 28223818.

81. Muiesan ML, Salvetti M, Virdis A, et al. Serum uric acid, predicts heart failure in a large Italian cohort: search for a cut-off value the URic acid Right for heArt Health study. J Hypertens. 2021; 39(1): 62-69, doi: 10.1097/HJH.0000000000002589, indexed in Pubmed: 32694342.

82. Huang G, Qin J, Deng X, et al. Prognostic value of serum uric acid in patients with acute heart failure: A meta-analysis. Medicine (Baltimore). 2019; 98(8): e14525, doi: 10.1097/ MD.0000000000014525, indexed in Pubmed: 30813158.

83. Casiglia E, Tikhonoff V, Virdis A, et al. Serum uric acid and fatal myocardial infarction: The URRAH (Uric Acid Right for Heart Health) study. J Hypertens. 2020; 38(3): 412-419, doi: 10.1097/ hjh.0000000000002287, indexed in Pubmed: 31644519.

84. Stack AG, Hanley A, Casserly LF, et al. Independent and conjoint associations of gout and hyperuricaemia with total and cardiovascular mortality. QJM. 2013; 106(7): 647-658, doi: 10.1093/qjmed/ hct083, indexed in Pubmed: 23564632.

85. Rahimi-Sakak F, Maroofi M, Rahmani J, et al. Serum uric acid and risk of cardiovascular mortality: a systematic review and doseresponse meta-analysis of cohort studies of over a million participants. BMC Cardiovasc Disord. 2019; 19(1): 218, doi: 10.1186/ s12872-019-1215-z, indexed in Pubmed: 31615412.

86. Lee SY, Park W, Suh YJu, et al. Association of serum uric acid with cardiovascular disease risk scores in Koreans. Int J Environ Res Public Health. 2019; 16(23), doi: 10.3390/ijerph16234632, indexed in Pubmed: 31766442.

87. Li Q, Li X, Wang J, et al. Diagnosis and treatment for hyperuricemia and gout: a systematic review of clinical practice guidelines and consensus statements. BMJ Open. 2019; 9(8): e026677, doi: 10.1136/bmjopen-2018-026677.

88. Tykarski A, Filipiak KJ, Januszewicz A, et al. Zasady postępowania w nadciśnieniu tętniczym - 2019 rok. Nadciśnienie Tętnicze w Praktyce. 2019; 5(1): 1-86.

89. Bardin T, Richette P. FAST: new look at the febuxostat safety profile. Lancet. 2020; 396(10264): 1704-1705, doi: 10.1016/ S0140-6736(20)32343-6, indexed in Pubmed: 33181079.

90. Mackenzie I, Ford I, Nuki G, et al. Long-term cardiovascular safety of febuxostat compared with allopurinol in patients with gout (FAST): a multicentre, prospective, randomised, open-label, non-inferiority trial. Lancet. 2020; 396(10264): 1745-1757, doi: 10.1016/s0140-6736(20)32234-0.

91. White WB, Saag KG, Becker MA, et al. Cardiovascular safety of febuxostat or allopurinol in patients with gout. N Engl J Med. 2018; 378(13): 1200-1210, doi: 10.1056/NEJMoa1710895, indexed in Pubmed: 29527974.
92. Keenan RT, Pillinger MH. Febuxostat: A new agent for lowering serum urate. Drugs of Today. 2009; 45(4): 247, doi: 10.1358/ dot.2009.045.004.1354217.

93. Becker MA, Schumacher HR, Wortmann RL, et al. Febuxostat compared with allopurinol in patients with hyperuricemia and gout. N Engl J Med. 2005; 353(23): 2450-2461, doi: 10.1056/ NEJMoa050373, indexed in Pubmed: 16339094.

94. Zhang T, Pope JE. Cardiovascular effects of urate-lowering therapies in patients with chronic gout: a systematic review and meta-analysis. Rheumatology (Oxford). 2017; 56(7): 1144-1153, doi: 10.1093/rheumatology/kex065, indexed in Pubmed: 28379501.

95. Joshi S, Parkar J, Ansari A, et al. Role of favipiravir in the treatment of COVID-19. Int J Infect Dis. 2021; 102: 501-508, doi: 10.1016/j.ijid.2020.10.069, indexed in Pubmed: 33130203.

96. Mishima E, Anzai N, Miyazaki M, et al. Uric acid elevation by favipiravir, an antiviral drug. Tohoku J Exp Med. 2020; 251(2): 87-90, doi: 10.1620/tjem.251.87, indexed in Pubmed: 32536670.

97. Pilkington V, Pepperrell T, Hill A. A review of the safety of favipiravir - a potential treatment in the COVID-19 pandemic? J Virus Eradication. 2020; 6(2): 45-51, doi: 10.1016/s20556640(20)30016-9.

98. Doi Y, Hibino M, Hase R, et al. A prospective, randomized, open-label trial of early versus late favipiravir therapy in hospitalized patients with COVID-19. Antimicrob Agents Chemother. 2020; 64(12), doi: 10.1128/AAC.01897-20, indexed in Pubmed: 32958718.

99. Williams B, Mancia G, Spiering W, et al. 2018 ESC/ESH Guidelines for the management of arterial hypertension. Eur Heart J. 2018; 31(33): 3021-3104, doi: 10.1093/eurheartj/ehy339, indexed in Pubmed: 30165516.

100. Matsumura K, Arima H, Tominaga M, et al. Effect of losar$\tan$ on serum uric acid in hypertension treated with a diuretic: the COMFORT study. Clin Exp Hypertens. 2015; 37(3): 192196, doi: 10.3109/10641963.2014.933968, indexed in Pubmed: 25051056.

101. Choi JW, Ford ES, Gao X, et al. Sugar-sweetened soft drinks, diet soft drinks, and serum uric acid level: the Third National Health and Nutrition Examination Survey. Arthritis Rheum. 2008; 59(1): 109-116, doi: 10.1002/art.23245, indexed in Pubmed: 18163396.

102. Ralston SH, Capell HA, Sturrock RD. Alcohol and response to treatment of gout. Br Med J (Clin Res Ed). 1988; 296(6637): 1641-1642, doi: 10.1136/bmj.296.6637.1641-a, indexed in Pubmed: 3135052.

103. Richette P, Poitou C, Manivet P, et al. Weight loss, xanthine oxidase, and serum urate levels: a prospective longitudinal study of obese patients. Arthritis Care Res (Hoboken). 2016; 68(7): 1036-1042, doi: 10.1002/acr.22798, indexed in Pubmed: 26844534.

104. Chen JH, Wen CP, Wu SB, et al. Attenuating the mortality risk of high serum uric acid: the role of physical activity underused. Ann Rheum Dis. 2015; 74(11): 2034-2042, doi: 10.1136/annrheumdis-2014-205312, indexed in Pubmed: 25053714.

105. Jacob RA, Spinozzi GM, Simon VA, et al. Consumption of cherries lowers plasma urate in healthy women. J Nutr. 2003; 133(6): 1826-1829, doi: 10.1093/jn/133.6.1826, indexed in Pubmed: 12771324.

106. Schlesinger N. Dietary factors and hyperuricaemia. Curr Pharm Des. 2005; 11(32): 4133-4138, doi: 10.2174/13816120 5774913273, indexed in Pubmed: 16375734. 
107. Richette P, Doherty M, Pascual E, et al. 2016 updated EULAR evidence-based recommendations for the management of gout. Ann Rheum Dis. 2017; 76(1): 29-42, doi: 10.1136/annrheumdis-2016-209707, indexed in Pubmed: 27457514.

108. Borghi C, Perez-Ruiz F. Urate lowering therapies in the treatment of gout: a systematic review and meta-analysis. Eur Rev Med Pharmacol Sci. 2016; 20(5): 983-992, indexed in Pubmed: 27010159.

109. Neogi T, Dalbeth N, Stamp L, et al. Renal dosing of allopurinol results in suboptimal gout care. Ann Rheum Dis. 2017; 76(1): e1, doi: 10.1136/annrheumdis-2016-210352, indexed in Pubmed: 27582422.

110. Stamp LK, O’Donnell JL, Zhang M, et al. Using allopurinol above the dose based on creatinine clearance is effective and safe in patients with chronic gout, including those with renal impairment. Arthritis Rheum. 2011; 63(2): 412-421, doi: 10.1002/art.30119, indexed in Pubmed: 21279998.

111. Rees F, Jenkins W, Doherty M. Patients with gout adhere to curative treatment if informed appropriately: proof-of-concept observational study. Ann Rheum Dis. 2013; 72(6): 826-830, doi: 10.1136/ annrheumdis-2012-201676, indexed in Pubmed: 22679303.

112. Ramasamy SN, Korb-Wells CS, Kannangara DRW, et al. Allopurinol hypersensitivity: a systematic review of all published cases, 1950-2012. Drug Saf. 2013; 36(10): 953-980, doi: 10.1007/ s40264-013-0084-0, indexed in Pubmed: 23873481.

113. Hershfield MS, Callaghan JT, Tassaneeyakul W, et al. Clinical Pharmacogenetics Implementation Consortium guidelines for human leukocyte antigen-B genotype and allopurinol dosing. Clin Pharmacol Ther. 2013; 93(2): 153-158, doi: 10.1038/ clpt.2012.209, indexed in Pubmed: 23232549.
114. Hande K, Noone R, Stone W. Severe allopurinol toxicity. Am J Med. 1984; 76(1): 47-56, doi: 10.1016/0002-9343(84)90743-5.

115. Wei L, Fahey T, Struthers AD, et al. Association between allopurinol and mortality in heart failure patients: a long-term follow-up study. Int J Clin Pract. 2009; 63(9): 1327-1333, doi: 10.1111/j.17421241.2009.02118.x, indexed in Pubmed: 19691616.

116. Scirè CA, Rossi C, Punzi L, et al. Change gout: how to deal with this "silently-developing killer" in everyday clinical practice. Curr Med Res Opin. 2018; 34(8): 1411-1417, doi: 10.1080/03007995.2018.1454896, indexed in Pubmed: 29553292.

117. Saag KG, Fitz-Patrick D, Kopicko J, et al. Lesinurad combined with allopurinol: a randomized, double-blind, placebo-controlled study in gout patients with an inadequate response to standardof-care allopurinol (a US-based study). Arthritis Rheumatol. 2017; 69(1): 203-212, doi: 10.1002/art.39840, indexed in Pubmed: 27564409 .

118. Deeks ED. Lesinurad: a review in hyperuricaemia of gout. Drugs Aging. 2017; 34(5): 401-410, doi: 10.1007/s40266-017-0461-y, indexed in Pubmed: 28425024.

119. Pérez-Ruiz F, Jansen T, Tausche AK, et al. Efficacy and safety of lesinurad for the treatment of hyperuricemia in gout. Drugs Context. 2019; 8: 212581, doi: 10.7573/dic.212581, indexed in Pubmed: 31191704.

120. Dalbeth N, Jones G, Terkeltaub R, et al. Efficacy and safety during extended treatment of lesinurad in combination with febuxostat in patients with tophaceous gout: CRYSTAL extension study. Arthritis Res Ther. 2019; 21(1): 8, doi: 10.1186/s13075018-1788-4, indexed in Pubmed: 30616614. 